\title{
VIEWPOINT
}

\section{Vasomotion and nitric oxide bioactivity in diseased coronary arteries}

\author{
D Tousoulis, G J Davies, T Crake, P C Toutouzas
}

Heart 2002;87:320-321

\begin{abstract}
Atheromatous coronary stenoses are no longer considered to be passive structures, instead having the capacity for dynamic, often transient, change which may take the form of constriction or dilatation in response to either endogenous or external stimulation.
\end{abstract}

\section{NITRIC OXIDE AND CORONARY STENOSIS VASOMOTION}

The molecular basis of pathological coronary arterial function is unclear. However one significant component appears to involve the synthesis of nitric oxide from L-arginine, catalysed by isoforms of the enzyme nitric oxide synthase. Following the seminal observation by Furchgott and Zawadzki of the dependence of physiologic arterial dilatation on the integrity of the endothelium, ${ }^{8}$ nitric oxide was identified as the prime mediator of endothelium dependent vasodilatation.' Diseased coronary arteries in patients were found to constrict, instead of dilate, in response to acetylcholine. ${ }^{10}$ However, as acetylcholine not only stimulates endothelial nitric oxide production but also contracts vascular smooth muscle cells via their surface muscarinic receptors, the results of this clinical study could be interpreted in at least three ways. Firstly, that diseased coronary arteries have malfunctioning endothelium; secondly, that their smooth muscle constricts with abnormal intensity; and thirdly, that both interpretations are true.

These interpretations can be clarified a little by observing the response of atheromatous stenoses to substance $\mathrm{P}$ as the predominant action of the latter is to stimulate nitric oxide activity in endothelial cells with no direct vascular smooth muscle constrictor effect. A study of patients with stable angina showed that stenoses do dilate in response to substance P. $^{6}$ The response is abnormally small. However, so is the response to glyceryl trinitrate which is a direct stimulator of vascular smooth muscle cell relaxation. Therefore, endothelium in the region of atheromatous stenosis is producing nitric oxide and could even be producing a normal amount; however, this cannot be ascertained because of the constraint of the impaired muscular response.

There followed, over a period of two decades, an extensive series of clinical studies which showed a vasoconstrictor component to angina attacks which was not confined to patients with variant angina, but extended over a considerable range of patients with ischaemic heart disease. ${ }^{4}$ Consequently, atheromatous coronary stenoses are no longer considered to be passive structures: they are structures which have the capacity for dynamic, often transient, change which may take the form of constriction ${ }^{5}$ or dilatation ${ }^{6}$ in response to either endogenous or external (environmental) stimulation. Furthermore, even plaque rupture, commonly found in acute myocardial infarction, may be a consequence of dynamic changes within the previously stable plaque. Evidence of this includes the histological finding of inflammatory cells within these plaques. ${ }^{7}$

\section{COMPLEX STENOSIS MORPHOLOGY AND NITRIC OXIDE BIOACTIVITY}

Further evidence of nitric oxide production by diseased segments of coronary arteries comes from clinical studies using $\mathrm{N}$-monomethyl L-arginine (LNMMA) which is an inhibitor of nitric oxide synthase. Coronary stenoses constrict in response to LNMMA, providing evidence of nitric oxide activity. ${ }^{11}$ This constrictor response is even greater in stenoses with complex angiographic morphology, suggesting even greater

Abbreviations: iNOS, cytokine induced nitric oxide synthase; LNMMA, N-monomethyl t-arginine 
nitric oxide activity in this type of lesion. ${ }^{12}$ Clinical studies have also shown that stenoses of complex morphology also constrict with greater intensity in response to vasoconstrictor agents. ${ }^{513}$ These stenoses are therefore complex, not only morphologically, but also histologically ${ }^{14}$ and functionally. In this regard, it is of interest that they are associated with unstable coronary syndromes.

Whatever the nitric oxide generating capacity of the endothelium may be in diseased coronary segments, this endothelium is certainly functionally defective in some manner and to some extent. For example, the stenoses do not respond to atrial pacing, unlike epicardial segments of normal arteries which dilate in response to the pacing induced increase in epicardial coronary flow velocity. ${ }^{15}$ The degree of impairment of stimulated endothelial production of nitric oxide may therefore depend on the nature of the stimulus rather than loss of the intracellular pathway of nitric oxide production.

The identity of the cell type responsible for nitric oxide production in diseased arteries is not clear. It could be the remaining partly or fully functioning endothelial cells lining the lumen of the epicardial segment, endothelial cells of the neomicrovasculature found within atheromatous plaques, macrophages within the lesion, or combinations of these together with other unknown cellular sources. As for molecular pathology, cytokine induced nitric oxide synthase (iNOS) is probably partly responsible for this pathological nitric oxide activity. Ex vivo immunohistochemical studies of atheromatous coronary artery have demonstrated iNOS activity within the lesion. ${ }^{16}$

\section{CONCLUSIONS}

In summary, atheromatous coronary artery plaques are functionally active and complex, particularly when their morphology is complex. A tendency to constriction and thrombosis are manifestations of the functional pathology, but there are also pathological compensatory mechanisms which may counterbalance these and prevent clinical instability. The latter is exemplified by the regeneration of nitric oxide activity by the pathological induction of nitric oxide synthase.

\section{Authors' affiliations}

D Tousoulis, P C Toutouzas, Cardiology Unit, Athens University Medical School, Athens, Greece

G J Davies, Division of Cardiology, Hammersmith Hospital, London, UK
T Crake Department of Cardiology, St Bartholemew's Hospital, London, UK

Correspondence to: Graham J Davies, Division of Cardiology, Hammersmith Hospital, Du Cane Road, London W12 ONN, UK. gidavies@hhnt.org

\section{REFERENCES}

1 Prinzmetal M, Kennamer R, Merliss R, et al. Angina pectoris. I. A variant of angina pectoris: preliminary report. Am J Med 1956;27:375-88.

2 Maseri A, L' Abbate A, Baroldi G, et al. Coronary vasospasm as a possible cause of myocardial infarction: a conclusion derived from the study of "preinfarction" angina. N Engl J Med 1978;299:1271-7.

3 Maseri A, Davies GJ, Hackett D, et al. Coronary artery spasm and vasoconstriction. The case for the distinction. Circulation 1990; 81:1983-91.

4 Kaski JC, Tousoulis D, Haider WA, et al. Reactivity of eccentric and concentric stenoses in chronic stable angina. J Am Coll Cardiol $1991 ; 17: 627-33$

5 Tousoulis D, Davies G, McFadden E, et al. Coronary vasomotor effects of serotonin in patients with angina. Relationship to coronary stenosis morphology. Circulation 1993:88 part 1):1518-26.

6 Tousoulis D, Tentolouris C, Crake T, et al. Effects of L- and D-arginine on the basal tone of human diseased coronary arteries and their responses to substance P. Heart 1999;81:505-11.

7 van der Wal $A C$, Becker $A E$, van der Loos $C M$, et al. Site of intimal rupture or erosion of thrombosed coronary atherosclerotic plaques is characterized by an inflammatory process irrespective of the dominant plaque morphology. Circulation 1994;89:36-44.

8 Furchgott RF, Zawadzki JV. The obligatory role of endothelial cells in the relaxation of arterial smooth muscle by acetylcholine. Nature 1980;288:373-6.

9 Palmer RMJ, Ashton DS, Moncada S. Vascular endothelial cells synthesize nitric oxide from L-arginine. Nature 1988;333:664-6.

10 Ludmer PL, Selwyn AP, Shook TL, et al. Paradoxical vasoconstriction induced by acetylcholine in atherosclerotic coronary arteries. N Engl J Med 1986;315:1046-51.

11 Tousoulis D, Davies GJ, Tentolouris C, et al. Effects of inhibition of nitric oxide synthesis in patients with coronary artery disease and stable angina. Eur Heart J 1997; 18:608-13.

12 Tousoulis D, Tentolouris C, Crake T, et al. Complex stenosis morphology and vasomotor response to inhibition of nitric oxide synthesis. Heart 2000; 84:529-34.

13 Tousoulis D, Crake T, Kaski JC, et al. Enhanced vasomotor responses of complex stenoses to acetylcholine in patients with chronic stable angina. Am J Cardiol 1995;75:725-8.

14 Davies MJ. The pathophysiology of acute coronary syndromes. Heart 2000;83:361-6.

15 Tousoulis D, Tentolouris C, Crake T, et al. Basal and flow-mediated nitric oxide production by atheromatous coronary arteries. J Am Coll Cardiol 1997;29:1256-62.

16 Buttery LDK, Springall DR, Chester AH, et al. Inducible NO synthase is present within human atherosclerotic lesions and promotes the formation and activity of peroxynitrite. Lab Invest 1996;75:77-85. 